\title{
Analysis of the possibility of using an engine with a rotating piston as the propulsion of an electric generator in application to a motor glider propulsion
}

Analysis of the possibility of using an engine with a rotating piston as the propulsion of an electric generator in application to a motor glider propulsion The paper presents an analysis of the possibilities of application of a rotating piston engine (Wankel type) as a propulsion for an electric generator in the motor glider propulsion system. This generator would be a part of the propulsion system of a hybrid motor glider using the AOS 71 motor glider airframe. In the research, the rotational characteristics of the LCR 407ti engine were determined experimentally. Driving torque run, power and fuel consumption were determined as a function of engine speed. The obtained results are presented in diagrams. The conceptual diagram of the hybrid drive is presented. The current generator was selected and the effectiveness of the generator and the entire propulsion were assessed from the motor glider's performance point of view. On the basis of the conducted research, conclusions were drawn and there were indicated the objectives and directions of further research on hybrid propulsion with specific aerodynamic and mass limitations of the aircraft

Key words: hybrid, combustion engines, motor glider, rotary engine, Wankel engine, hybrid propulsion

\section{Introduction - the issue of the application of new types of aircraft propulsion \\ For many years, the trend of reducing fuel consumption} and improvement of ecological indicators has been observed in transport. These processes also do not bypass broadly understood air transport. Aircraft companies and leading research centres are undertaking work on various technical solutions. These may be aircraft equipped with an all-electric propulsion (UAV, Pipistrel Pantera, Airbus EFan, AOS-71). The basic disadvantage of electric propulsion systems used in aircraft constructions is their mass. The high mass of batteries with a relatively small capacity, causes a low value of the density of energy stored on the deck - compared, for example, to the density of energy accumulated in hydrocarbon fuel. These features affect the limited range or durability of flight. In addition, these parameters influence the increased demand for power during the manoeuvres, such as start or climb. Therefore, it seems interesting (until the development of an energy source with a sufficient energy density) to develop an aeronautical hybrid propulsion system that would allow to increase the operating parameters of the aircraft.

This paper presents the concept of using a hybrid system (consisting of a combustion engine and electric generator) designed for propulsion of a modified AOS 71 motor glider. A number of simplifying assumptions were adopted for the conceptual computations: no additional mass of electrical installation required for physical connection of the assemblies, nor the mass of additional devices to control the propulsion

\section{Description of the research object}

The basis for the analysis was the airframe of the electric AOS-71 (Fig. 1), built as part of the cooperation between the Department of Aircraft and Aircraft Engines of the Rzeszow University of Technology and the Faculty of Power and Aeronautical Engineering of the Warsaw University of Technology.

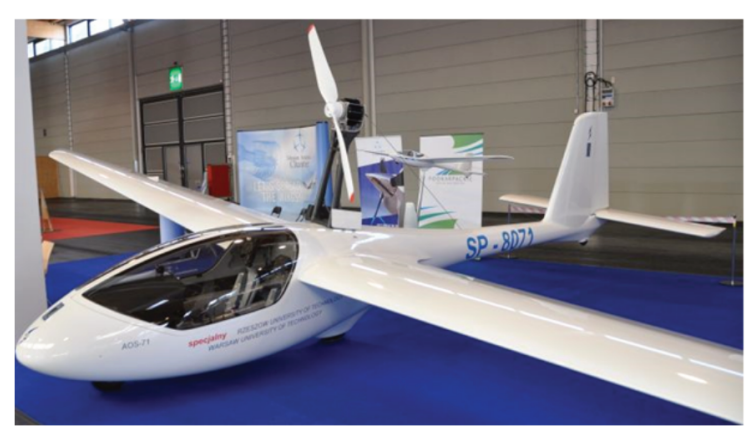

Fig. 1. The AOS 71 motor glider

Table 1 shows the basic data of the airframe, while Figures 2 and 3 present the values of power required for the flight for this airframe and the efficiency of its propeller depending on the flight speed.

Table 1. Basic data of the AOS 71 motor glider $[6,7]$

\begin{tabular}{|l|c|c|}
\hline Wing area & $\mathrm{S}\left[\mathrm{m}^{2}\right]$ & 15.8 \\
\hline Wing span & $\mathrm{R}[\mathrm{m}]$ & 16.4 \\
\hline Aspect ratio & $\Lambda$ & 17 \\
\hline Maximum take-off mass & $\mathrm{M}_{\max }[\mathrm{kg}]$ & 660 \\
\hline Minimum motor glider mass & $\mathrm{M}_{\min }[\mathrm{kg}]$ & 500 \\
\hline
\end{tabular}

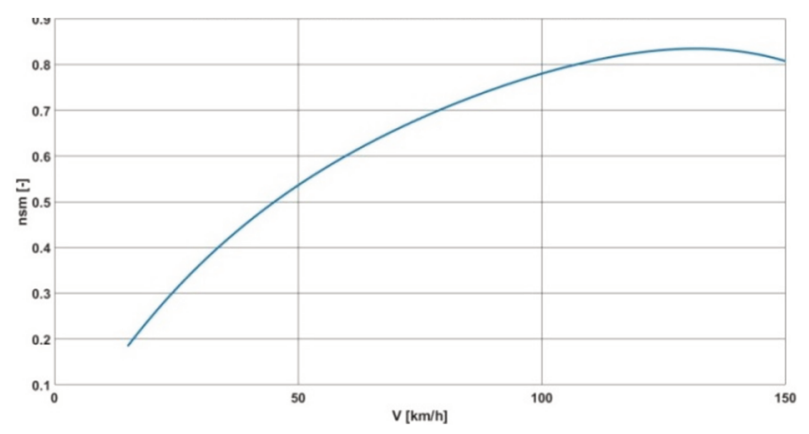

Fig. 2. Efficiency of propeller in the function of flight speed - for the AOS 71 motor glider $[6,7]$ 


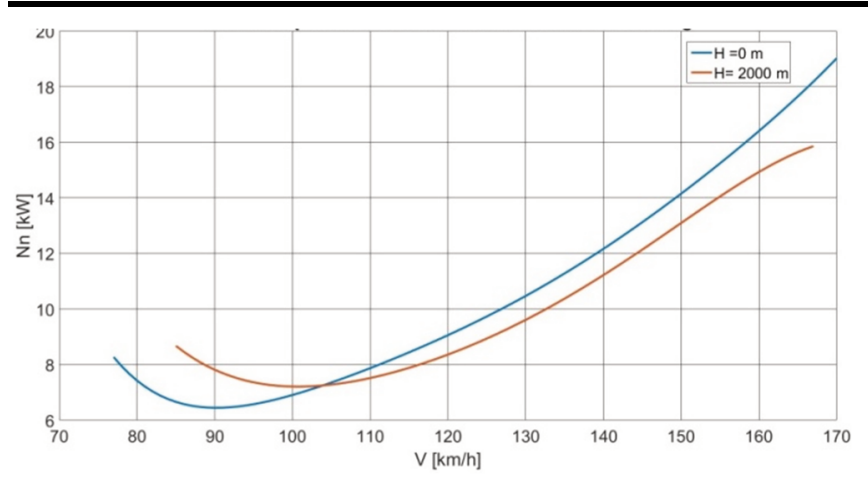

Fig. 3. Power required for flight in the function of flight speed - for the AOS 71 motor glider; $M_{\max }=660 \mathrm{~kg}[6,7]$

The motor glider is powered by the Emrax 228 engine and a battery assembly of the parameters given in Table 2 .

Table 2. Technical data of the AOS 71 power unit $[6,7]$

\begin{tabular}{|l|c|c|}
\hline Engine & Emrax 228 & - \\
\hline Continuous power & $\mathrm{N}_{\text {const }}[\mathrm{kW}]$ & 55 \\
\hline Peak power & $\mathrm{N}_{\max }[\mathrm{kW}]$ & 100 \\
\hline Continuous torque & $\mathrm{M}_{\text {const }}[\mathrm{Nm}]$ & 120 \\
\hline Engine mass & $\mathrm{m}_{\mathrm{s}}[\mathrm{kg}]$ & 12 \\
\hline Battery type & $\mathrm{Li}-\mathrm{Pol}$ & - \\
\hline Capacity & $\mathrm{C}[\mathrm{Ah}]$ & 40 \\
\hline Voltage & $\mathrm{U}_{\text {bat }}[\mathrm{V}]$ & 180 \\
\hline Battery mass & $\mathrm{m}_{\text {bat }}[\mathrm{kg}]$ & 178 \\
\hline
\end{tabular}

For these data, the energy accumulated on-board is determined from the formula:

$$
\mathrm{E}=\mathrm{C} \cdot \mathrm{U}_{\mathrm{bat}}=\mathrm{I} \cdot 3600[\mathrm{~s}] \cdot \mathrm{U}_{\mathrm{bat}}
$$

where : $\mathrm{E}[\mathrm{J}]$ - energy accumulated on-board for battery parameters presented in Table 2; this value was $\mathrm{E}=25920 \mathrm{~kJ}$.

For such flight stages as climb or horizontal flight, it is possible to determine the energy required to perform a given manoeuvre and, as a consequence, determine the flight duration and range of the aircraft.

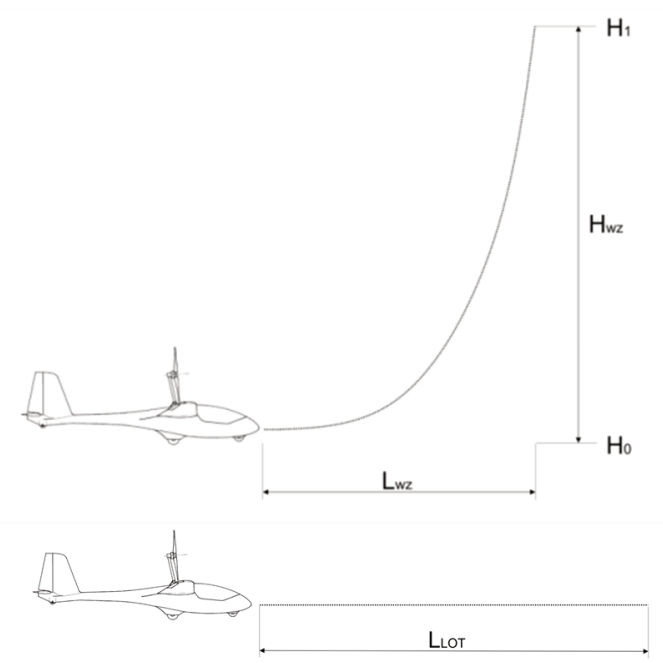

Fig. 4. Flight stages - climb (up) and horizontal flight (down) $[1,8]$ :

The climb time can be determined from the dependence

$$
\mathrm{t}_{\mathrm{wz}}=\frac{\mathrm{H}_{1}-\mathrm{H}_{\mathrm{o}}}{\mathrm{w}}
$$

where: H0, H1 - initial and final altitude, W - the climb velocity determined as the product of the flight speed and the trigonometric function of the climb angle [1]:

$$
\mathrm{W}=\mathrm{V} \cdot \sin \theta
$$

The energy required to perform the climb is determined from the formula [1]:

$$
\mathrm{E}_{\mathrm{wZ}}=\left(\mathrm{m} \cdot \mathrm{g} \cdot \mathrm{W} \cdot \mathrm{t}_{\mathrm{wz}}+\mathrm{N}_{\mathrm{n}} \cdot \mathrm{t}_{\mathrm{wz}}\right) \div \eta_{\mathrm{sm}}
$$

where: $E_{w z}$ - total energy of climb, $m$ - aircraft mass (before the manoeuvre), $g$ - gravitational acceleration, $\mathrm{N}_{\mathrm{n}}-$ power required for horizontal flight, $\mathrm{t}_{\mathrm{WZ}}$ - duration of the climb, $\eta_{\mathrm{sm}}-$ propeller efficiency.

The energy required for horizontal flight can be determined from the formula [1]:

$$
E_{L}=\left(N_{n} \cdot t_{L}\right) \div \eta_{s m}
$$

where: $t_{L}$ - horizontal flight time.

Figure 5 presents the energy required for the flight of the AOS-71 motor glider depending on the flight speed assuming different flight durability.

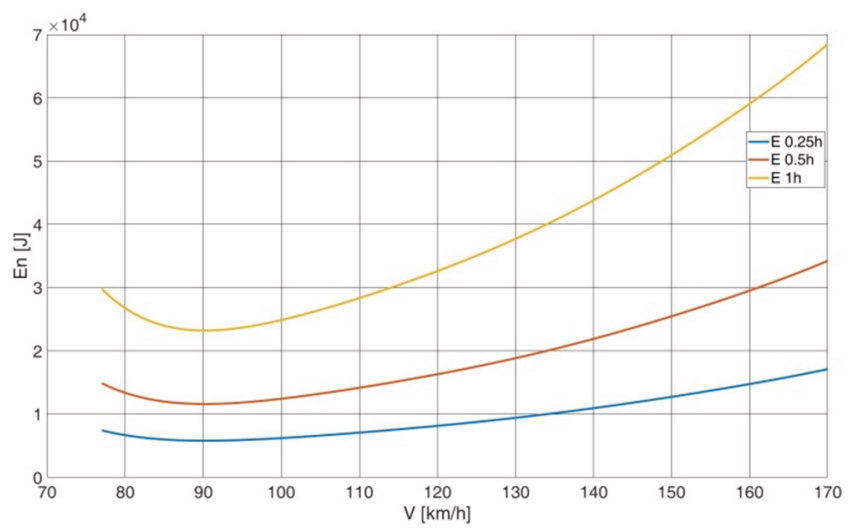

Fig. 5. The course of the change of energy required for the flight as a function of the flight speed

Knowing the energy demand for given flight stages and the value of energy accumulated on board, it is possible to determine the flight range and duration for given flight parameters. These data constituted the starting point for selection of an electric generator and a set of batteries.

\section{Selection of an electric generator and performance comparison}

A serial hybrid was taken for further analysis in the construction scheme where the combustion engine does not have a kinematic connection with the propeller. It was assumed that the internal combustion engine only recharges the battery or can provide the necessary excess power in the critical stages of the flight (e.g. start, climb).

The Wankel AG 407TGi rotary piston engine was used to build the generator propulsion model. This choice was dictated by the advantages of rotary piston engines, such as low engine mass, low level of vibrations generated by it, and high drive torque compared to reciprocating piston engines. Table 3 presents the comparison of selected data of several internal combustion engines with a similar power range used in general aviation. 
Table 3. Technical data of internal combustion engines $[9,10]$

\begin{tabular}{|l|c|c|c|c|}
\hline Engine & & $407 \mathrm{TGi}$ & $\begin{array}{c}\text { Rotax } \\
125\end{array}$ & $\begin{array}{c}\text { Rotax } \\
28 \\
\text { Max }\end{array}$ \\
\hline $\begin{array}{l}\text { Maximum engine } \\
\text { power }\end{array}$ & $\mathrm{N}_{\max }[\mathrm{kW}]$ & 31.5 & 25 & 28 \\
\hline Maximum torque & $\mathrm{M}_{\max }[\mathrm{Nm}]$ & 51 & 22 & - \\
\hline Engine mass & $\mathrm{m}_{\mathrm{s}}[\mathrm{kg}]$ & 20 & 29 & 58 \\
\hline $\begin{array}{l}\text { Revolutions for } \\
\mathrm{M}_{\max }\end{array}$ & $\begin{array}{c}\mathrm{n}_{\mathrm{Mmax}} \\
{[\mathrm{rev} / \mathrm{min}]}\end{array}$ & 4000 & 10500 & - \\
\hline
\end{tabular}

Table 3 shows that the Wankel engine has a relatively high unit power indicator (power related to the dry engine mass) for the remaining engines. In addition, it has a much higher torque than the 1-cylinder Rotax engine, which is available at low rotational speed. An additional advantage of using this type of engine will be less vibrations generated by a rotary piston engine than a traditional high-speed single-cylinder unit, which will favourably affect the fatigue strength of the engine and airframe structure.

In order to select the generator set properly, the rotational characteristics (power in the function of revolution) of the rotary piston engine (Wankel 407TGi) were measured. Figure 6 shows the view of the test stand with an electro-swirl brake.

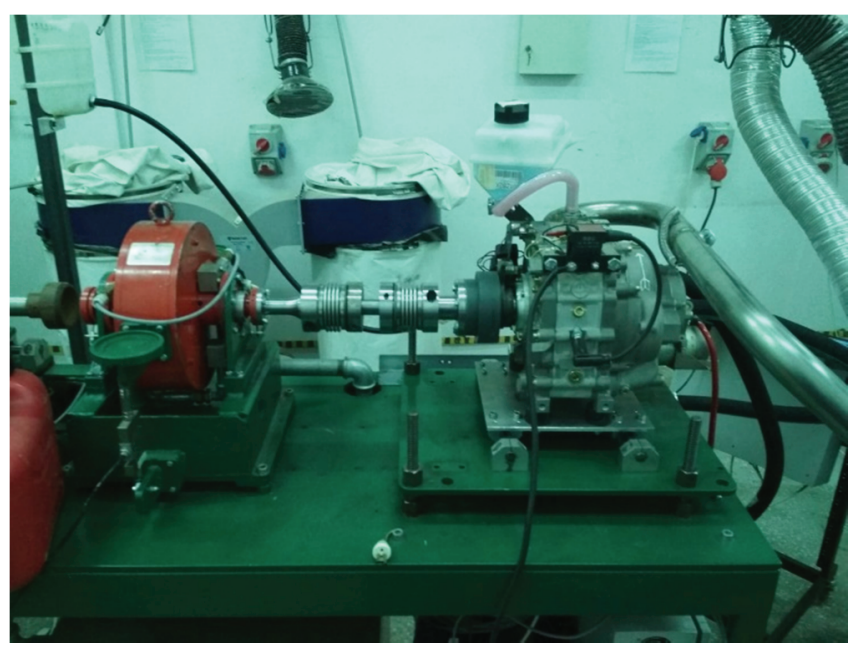

Fig. 6. Stand for testing engine characteristics

Figure 7 shows the dependence of power and drive torque as well as specific fuel consumption in the a function of the rotational speed of the tested engine. Fuel consumption characteristics are not available in the engine manual, hence the need to determine them.

The analysis of the characteristics shows that for the value of maximum torque there is the highest efficiency of the engine and associated with it the lowest specific fuel consumption. The maximum torque is around $4000 \mathrm{rpm}$, which corresponds to the power of $22 \mathrm{~kW}$ and the specific fuel consumption of $0.3 \mathrm{~kg} / \mathrm{kWh}$. The analysis was based on the aerodynamic and performance characteristics of the airframe, the horizontal flight velocity $\mathrm{V}=100 \mathrm{~km} / \mathrm{h}$ and the vertical velocity (climb) $\mathrm{W}=2.3 \mathrm{~m} / \mathrm{s}$.

Giving the formula (3) as follows [1]:

$$
\mathrm{W}=\mathrm{V} \cdot \sin \theta=\frac{\mathrm{N}_{\mathrm{r}}-\mathrm{N}_{\mathrm{n}}}{\mathrm{m} \cdot \mathrm{g}}
$$
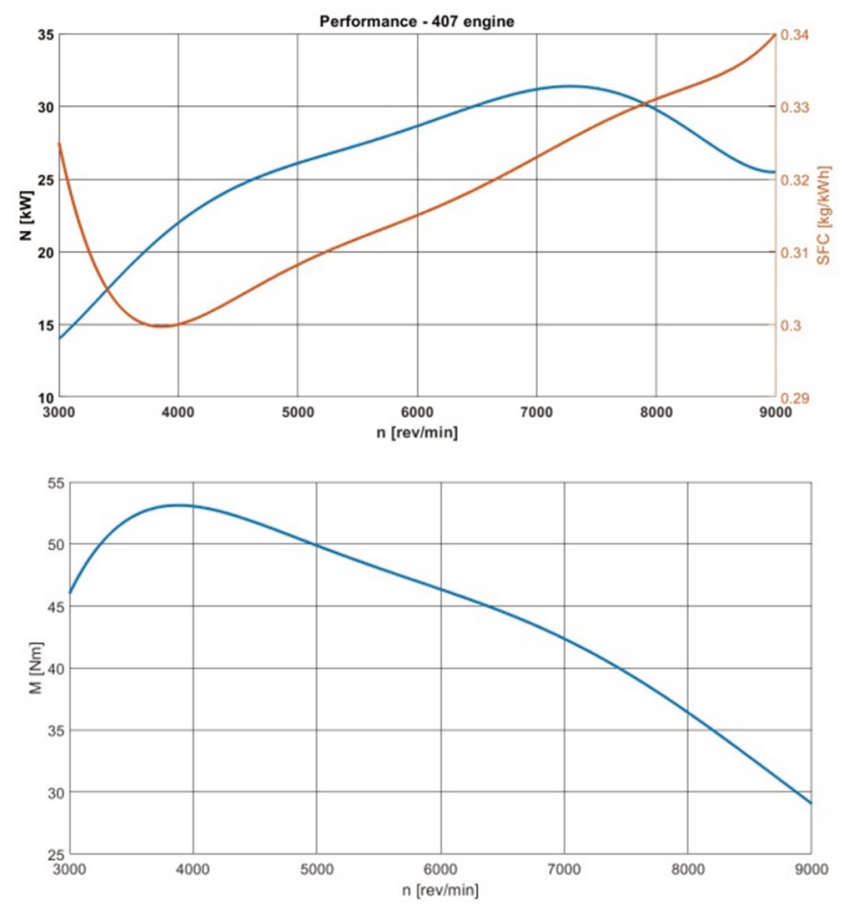

Fig.7. Rotational characteristics of the 407 tgi engine (a- power curve, btorque curve in the function of rotational speed)

there can be determined the power generated by the $\mathrm{N}_{\mathrm{r}}$ power unit, which is required to obtain the climb parameters. For the adopted aerodynamic parameters of the motor glider during the climb, the power of $\mathrm{N}_{\mathrm{r}}$ is about $20 \mathrm{~kW}$. Taking into account the efficiency of energy transformation in the propulsion system, the calculated power is $22 \mathrm{~kW}$, which is the value that meets the power requirement to perform the climb manoeuvre.

For this power range, the Emrax 188 engine was chosen as the alternator with the following technical data (given in Table 4).

Table 4. Technical data of the Emrax 188 engine[11]

\begin{tabular}{|l|c|c|}
\hline Engine & Emrax 1888 & - \\
\hline Continuous power & $\mathrm{N}_{\text {const }}[\mathrm{kW}]$ & 32 \\
\hline Peak power & $\mathrm{N}_{\max }[\mathrm{kW}]$ & 50 \\
\hline Continuous torque & $\mathrm{M}_{\text {const }}[\mathrm{Nm}]$ & 60 \\
\hline Engine mass & $\mathrm{m}_{\mathrm{s}}[\mathrm{kg}]$ & 6.8 \\
\hline
\end{tabular}

Together with the factory-dedicated control system [lit], this engine is able to operate in generator mode with the efficiency of $98 \%$.

The fuel tank holds $7 \mathrm{~kg}$ of oil-gasoline mixture (1:80). The selected generator set works with a set of batteries of the parameters given in Table 5 .

Table 5. Specifications of the hybrid battery set

\begin{tabular}{|l|c|c|}
\hline Battery type & Li-Pol & - \\
\hline Capacity & $\mathrm{C}[\mathrm{Ah}]$ & 16 \\
\hline Voltage & $\mathrm{U}_{\text {bat }}[\mathrm{V}]$ & 355 \\
\hline Battery mass & $\mathrm{m}_{\text {bat }}[\mathrm{kg}]$ & 60 \\
\hline
\end{tabular}

The energy accumulated on-board can be determined by modifying the dependence (1) to the form[1]:

$$
\mathrm{E}=\mathrm{I} \cdot 3600[\mathrm{~s}] \cdot \mathrm{U}_{\text {bat }}+\eta_{\text {gen }} \cdot\left(\mathrm{N}_{\mathrm{s}} \cdot \mathrm{t}_{\mathrm{s}}\right)
$$


were $\mathrm{t}_{\mathrm{s}}$ - generator working time

$$
\mathrm{t}_{\mathrm{s}}=\frac{\mathrm{m}_{\mathrm{pal}}}{\mathrm{SFC} \cdot \mathrm{N}_{\mathrm{s}}}
$$

where SFC - specific fuel consumption, $\mathrm{N}_{\mathrm{s}}$ - engine power during generator operation mode.

With the above assumptions, the starting mass in relation to the constructed and functioning electric variant of AOS 71 did not change and amounts to $660 \mathrm{~kg}$.

\section{Determining the performance of a hybrid power unit}

For the propulsion hybrid system, calculations of the performance parameters of the power unit and motor glider were made. The results are presented in the diagrams in Figs 8 and 9.

Figure 8 shows the amount of energy accumulated onboard for the hybrid and electric variants.

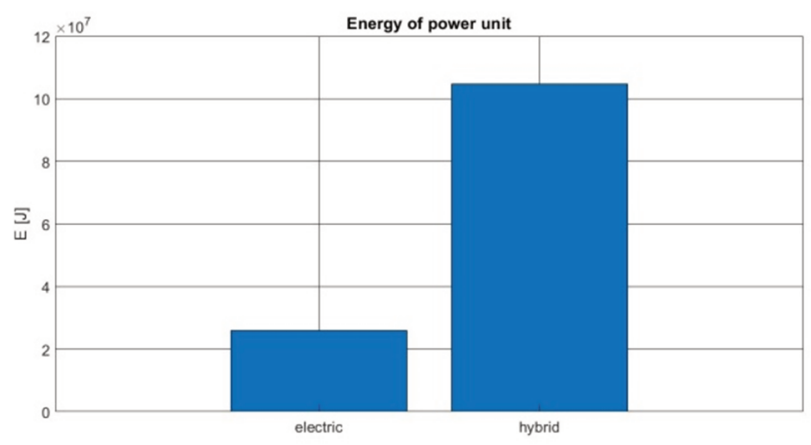

Fig. 8. The amount of energy accumulated on-board

Figure 9 shows the energy density in relation to the take-off mass.

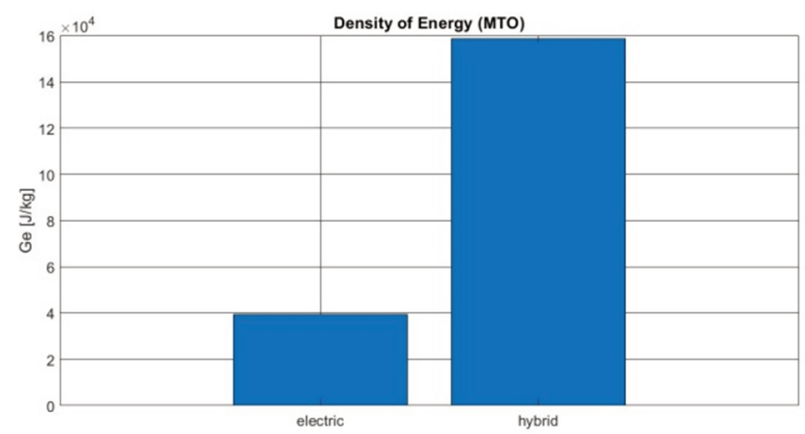

Fig. 9. Comparison of the energy density on-board the motor glider for two propulsion variants, in relation to the take-off mass

Figure 10 shows the range of the motor glide, assuming a flight duration up to depletion of the energy resource, and Figure 11 presents the flight duration corresponding to this assumption.

\section{Bibliography}

[1] ANDERSON, J. Introduction to flight. McGraw Hill Book Company. San Francisco 2003.

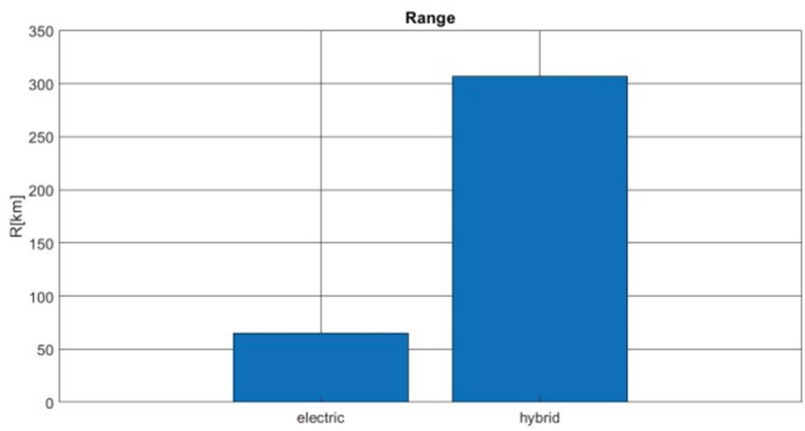

Fig. 10. The range of the motor glide, assuming a flight duration up to depletion of the energy resource

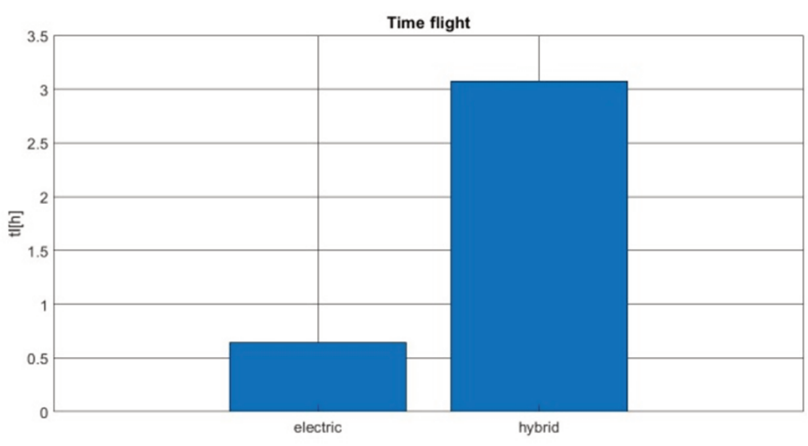

Fig. 11. The flight duration [h], assuming a flight duration up to depletion of the energy resource

\section{Results of research conducted and conclusions}

The hybrid propulsion provided more than a 5-fold increase in the range and flight time while maintaining the condition of the same take-off mass. It was connected with 4-times more energy accumulated on-board the motor glider. In Fig. 9, showing the energy density related to the takeoff mass, the problem of the high mass of the battery in relation to the energy that can be accumulated is shown. The calculations show that the hybrid propulsion variant is an attractive option for the motor glider, both in the mass and economic terms. Despite the extension and complexity of the propulsion in the construction sense, it allows to keep the starting mass unchanged in relation to the electric variant. The high density of hydrocarbon fuel energy allows for a greater (almost 6-fold) range and duration of the flight in relation to the electric drive. In the mass calculations, the increase of mass of the propulsion set due to the necessity of installing electric wires and controllers was not taken into account. Detailed research, taking into account these problems, will be continued.

\section{Acknowledgements}

The research presented in this paper was financed as project PBS3/A6/24/2015 "AOS-H2" of the Applied Research Programme (PBS) of the National Centre for Research and Development (NCBIR), Poland, in the years 2015-19.
[2] BOJOI, R., BOGGERO, H. et al. Multiphase drives for hybrid-electric propulsion in light aircrafts: a viable solution. Conference: 2018 International Symposium on Power 
Electronics, Electrical Drives, Automation and Motion (SPEEDAM). DOI: 10.1109/SPEEDAM.2018.8445241

[3] GEISS, I., VOIT-NITSCHMANN, R. Sizing of fuel-based energy systems for electric aircrafts. Proceedings of the Institution of Mechanical Engineers Part G-Journal of Aerospace Engineering. 2017, 231. DOI: 10.1177/09544100177 21254

[4] FAHIM, M. An overview of double-bar single-wheel rotary combustion engine. Advances in Mechanical Engineering. 2019, 11(2), 1-13. DOI: 10.1177/1687814019828074

[5] JAKUBOWSKI, R., ORKISZ, M. A review of selected alternative propulsion systems for UAV applications. Zeszy-

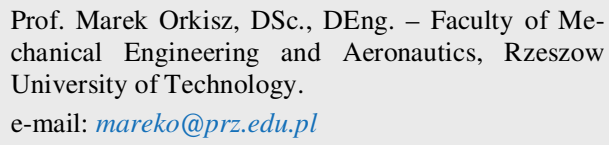

Michał Kuźniar, MEng. - Faculty of Mechanical Engineering and Aeronautics, Rzeszow University of Technology.

e-mail:mkuzniar@prz.edu.pl ty Naukowe/Wyższa Szkoła Oficerska Sit Powietrznych Dęblin. 2015. 231. DOI: 10.1177/0954410017721254

[6] MARIANOWSKI, J., FRĄCZEK, W., CZARNOCKI, F. Założenia podstawowe dla projektu motoszybowca AOSH2. (not publish)

[7] MARIANOWSKI, J., TOMASIEWICZ, J., CZARNOCKI, F. Analiza masowa motoszybowca AOS-H2. (not publish)

[8] ROSKAM, J. Airplane aerodynamics and performance. DARcorporation. Kansas 2016.

[9] WANKEL AG, Wankel engine manual

[10] www.flyrotax.com

[11] www.emrax.com

Piotr Wygonik, DEng. - Faculty of Mechanical Engineering and Aeronautics, Rzeszow University of Technology.

e-mail: piowyg@prz.edu.pl

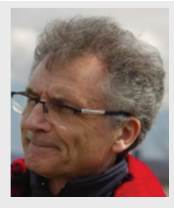

Maciej Kalwara, MEng. - Faculty of Mechanical Engineering and Aeronautics, Rzeszow University of Technology.

e-mail:kalmac@prz.edu.pl 